\title{
Multi-parameter scoring functions for ligand- and structure-based de novo design
}

\author{
Fabian Bös ${ }^{1 *}$, KM Smith², Q Liư \\ From 5th German Conference on Cheminformatics: 23. CIC-Workshop \\ Goslar, Germany. 8-10 November 2009
}

Successful drug discovery often requires optimization against a set of biological and physical properties. We describe de novo design studies that demonstrate successful scaffold hops between known classes of ligands for p38 MAP kinases using ligand-based and structurebased multi-parameter scoring functions coupled to the molecular invention engine Muse.

The ligand-based scoring function includes pharmacophoric and steric tuplets and structural (fingerprint based) similarity. In addition various selectivity or ADME related properties (e.g. Lipinski properties, polar surface area, activity at off-targets, etc.). can be taken into account to guide the evolution of structures meeting multiple design criteria.

The structure-based scoring function uses SurflexDock to pose and score invented structures inside the target's active site. In addition, a number of simple molecular properties (e.g. $\operatorname{cog} \mathrm{P}$, Lipinski properties, etc.) are used as score components to focus the design on medicinally relevant chemistries. With the ability of Surflex-Dock to start the docking process with a single or multiple placed fragments, this scoring function can be applied in fragment based drug discovery to optimize attachments onto a pre-placed substructure.

\section{Author details}

${ }^{1}$ Tripos International, Martin-Kollar-Str. 17, 81829 München, Germany.

${ }^{2}$ St. Louis, USA. ${ }^{3}$ Shanghai, PR China.

Published: 4 May 2010

doi:10.1186/1758-2946-2-S1-P31

Cite this article as: Bös et al: Multi-parameter scoring functions for ligand- and structure-based de novo design. Journal of Cheminformatics 2010 2(Suppl 1):P31.

Tripos International, Martin-Kollar-Str. 17, 81829 München, Germany
Publish with ChemistryCentral and every scientist can read your work free of charge

"Open access provides opportunities to our colleagues in other parts of the globe, by allowing anyone to view the content free of charge."

W. Jeffery Hurst, The Hershey Company.

- available free of charge to the entire scientific community

- peer reviewed and published immediately upon acceptance

- cited in PubMed and archived on PubMed Central

- yours - you keep the copyright

Submit your manuscript here:

http://www.chemistrycentral.com/manuscript/

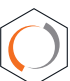
Chemistry Central 